\title{
BMJ Open Quality Stent cards: a simple solution for forgotten stents?
}

\author{
Masood Moghul, ${ }^{\circledR}$ Stefanos Almpanis
}

To cite: Moghul M, Almpanis S. Stent cards: a simple solution for forgotten stents? BMJ Open Quality 2019;8:e000612. doi:10.1136/ bmjoq-2018-000612

Received 20 December 2018 Revised 11 April 2019 Accepted 23 April 2019

Check for updates

(C) Author(s) (or their employer(s)) 2019. Re-use permitted under CC BY-NC. No commercial re-use. See rights and permissions. Published by BMJ.

Department of Urology, North Middlesex University Hospital NHS Trust, London, UK

Correspondence to Dr Masood Moghul, North Middlesex University Hospital NHS Trust, London, UK; masood.moghul@doctors.org.uk
Since first being used in the 1960s, ureteric JJ stents have rapidly expanded the arsenal of all urological fields worldwide, from the emergency management of obstruction, reducing morbidity poststone surgery or in renal cancer surgery. ${ }^{1}$ However, despite their benefits stents often cause issues to patients, namely, pain and recurrent infections. Perhaps the more dangerous risk is to those patients who do not feel such symptoms, or are unable to communicate so. They are less likely to seek medical attention if the stent is left in for a prolonged period. The risk of forgotten stents cannot be underestimated with morbidity including encrustation, fistula formation, loss of renal function from the corresponding kidney and even mortality. ${ }^{2}$ The large-scale use of JJ stents, across different specialities (urology, transplant surgery, interventional radiology) adds to the difficulty in keeping a record of them. ${ }^{3}$

In the UK, forgotten stents are considered a 'never event' and hence can also be a source of significant litigation for hospitals and doctors. ${ }^{4}$

Various measures have been used to reduce their occurrence, namely electronic stent registers have been employed in many hospitals. These often require manual entry of patient identifiers with a desirable date for stent removal or replacement. Predetermined time reminders are sent to ensure that patient is not forgotten. However, stent registers may not help get around the reliance on the surgeon to input the correct data and further issues occur when a patient has moved away from the region or is unable to respond to hospital communications. Biodegradable stents have been used although there is inconsistency with the time taken to degrade. ${ }^{5}$ Patient wristbands ${ }^{3}$ reminding patients and carers that a stent is in situ have also been developed although they may not be a durable long-term solution.

To help increase the involvement of the patient, and provide them with clear information regarding their stent we propose the use of a 'stent card' to be given to patients on discharge from hospital as an additional method of reducing forgotten stents, alongside stent registers. The idea behind this was to develop a cost-effective mechanism to reduce the risk of forgotten stents, to remind patients to contact the hospital in the event that they have not had any communication for stent removal or exchange. The use of stent cards is based on the idea that other medical devices such as pacemakers and cardiac stents often come with corresponding medical device cards, why should we not do the same for stents?

We created a stent card (figure 1), to be given to patients on discharge from hospital following any procedure where a stent was inserted (including radiologically inserted antegrade stents). It documents the patient's details, the length of time the stent should remain and contact details for the patient to use if they have not received any dates for stent change or removal. The cards were produced by the urology department and are given by the operating surgeon along with the rest of the patient's paperwork, prior to being discharged.

We audited the frequency of forgotten stents in our department before and after implementation of this stent card. Forgotten stents for the purpose of this audit were defined as stents in situ for more than 6 months ${ }^{2}$; however, in practice at our institution the intended stent duration varies depending on the procedure performed and the nature of the need for a stent.

In our department, we annually perform around 250 stents per year. Prior to the stent card the number of forgotten stents was on average six per year $(2.4 \%)$. In the year subsequent to the implementation of the stent card, we found no forgotten stents. Although we cannot prove that implementation of the stent cards was the sole reason for this reduction in forgotten stents it is likely to have contributed. Patient feedback regarding stents has been overwhelmingly positive. It was also noted how in the process of explaining the stent card to patients extra 


\section{URETERIC STENT CARD}

Dear patient, you have an internal plastic tube called a urological stent, or JJ stent. It is designed to help pass urine from your kidney to your bladder.

This stent has an expiry date and must be removed or changed prior to this date.

- Please carry this card with you until the stent is removed.

- If a new stent is inserted you will then be given a new card.

Please contact us via the telephone numbers opposite if the expiry date is less than 1 month away and you have not heard from the hospital.
Name:

Hospital Number:

NHS Number:

\section{Urology Secretaries:}

Urology Admissions Department:

\section{Stent Expiry Date}

Figure 1 Stent card.

time and education is provided to them, which may not otherwise be the case.

The stent card is a cost-effective method to reduce the frequency of forgotten stents. It acts by increasing the education and level of responsibility of patients' and carers to contact the hospital department in the event that the stent is not removed when planned.

Acknowledgements We acknowledge that a version of this paper was presented at the American Urology Association Annual meeting in May 2018.

Contributors SA contributed to the planning, implementation and writing of the study. MM contributed to the implementation, data gathering and writing of the manuscript.

Funding The authors have not declared a specific grant for this research from any funding agency in the public, commercial or not-for-profit sectors.

Competing interests None declared.

Patient consent for publication Not required.

Provenance and peer review Not commissioned; externally peer reviewed.
Open access This is an open access article distributed in accordance with the Creative Commons Attribution Non Commercial (CC BY-NC 4.0) license, which permits others to distribute, remix, adapt, build upon this work non-commercially, and license their derivative works on different terms, provided the original work is properly cited, appropriate credit is given, any changes made indicated, and the use is non-commercial. See: http://creativecommons.org/licenses/by-nc/4.0/.

\section{REFERENCES}

1. Brotherhood $\mathrm{H}$, Lange $\mathrm{D}$, Chew $\mathrm{BH}$. Advances in ureteral stents. Transl Androl Urol 2014;3:314-9.

2. Sohrab A, Aneesh S, Sureka SK, et al. Forgotten reminders: an experience with managing 28 forgotten Double-J stents and management of related complications. Indian J Surg 2015;77(Suppl 3):1165-71.

3. Withington J, Wong $\mathrm{K}$, Bultitude $\mathrm{M}$, et al. The forgotten ureteric stent: what next? BJU Int 2014;113:850-1.

4. Osman NI, Collins GN. Urological litigation in the UK National health Service (NHS): an analysis of 14 years of successful claims. BJU Int 2011;108:162-5.

5. Chew BH, Lange D, Paterson RF, et al. Next generation biodegradable ureteral stent in a Yucatan pig model. J Urol 2010;183:765-71. 